\title{
PENGARUH PEMBAGIAN KERJA TERHADAP PENINGKATAN EFISIENSI KERJA KARYAWAN PASTRY DI HOTEL SANTIKA PREMIERE MALANG
}

\author{
Widia Prastyanti ${ }^{1)}$, Estikowati $^{2}$ \\ Program Diploma Kepariwisataan Universitas Merdeka Malang \\ Jl. Bandung No. 1 Malang
}

Korespondensi dengan Penulis :

Estikowati: Telp: 085234158071

E-mail: estiwin97@gmail.com

\begin{abstract}
The study was conducted to determine the effect of the division of labor on the work efficiency of pastry employees at Hotel Santika Premiere Malang. Work efficiency relates to the product produced with the resources used. While the division of labor is a separator type of work done by individuals. Researchers used the Simple Linear Regression Analyze method to predict how far the value of the dependent variable will be changed if the independent variable is changed. From result of research of independent variable $(X)$ that is Division of labor and dependent variable (Y) Work efficiency have significant relation. This is evidenced from the data processing is known significant value sebersar $0.003<0.05$, with the conclusion Ho rejected and Ha accepted that there is influence between the Division of labor (X) on Efficiency of work. From the questionnaire data the authors conclude that the existing division of labor is not appropriate for employees so that the level of efficiency of employees decreased.
\end{abstract}

Keyword: Division of work, Work Efficiency, Pastry

Setiap negara di belahan dunia

pasti memiliki daya tarik wisata untuk

dikunjungi, baik itu dari segi sejarah atau dunia kuliner. Tanpa kita sadari semakin hari seluruh negara di dunia berlomba- lompa mempromosikan negara mereka. Dunia pariwisata dapat dikatakan sebagai penunjang berkembangnya perekonomian suatu negara, tidak hanya itu teknologi pun ikut berkembang. Salah satu penunjang akomodasi untuk wisatawan yang penting adalah tempat menginap. Banyak jenis tempat penginapan yang digolongkan sesuai dengan harga, jenis daerah, dan fasilitas yang ditawarkan.

Dengan jumlah wisatawan yang meningkat tentu diimbangi dengan perkembangan pertumbuhan dan pembangunan hotel di suatu tempat. Hal itu juga terjadi di Indonesia, 
beberapa tahun terakhir tingkat pembangunan hotel meningkat di beberapa kota. Hotel yang terdahulunya memiliki fungsi sebagai sarana akomodasi tempat menginap kini mulai berkembang. Mulai dari tempat pertemuan bisnis, seminar hingga pernikahan.

Dalam perkembangan fungsi hotel tersebut banyak fasilitas penunjang yang dilibatkan dalam operasional hotel, Salah satunya ada Food and Beverage Department. Dimana departmen tersebut meruapakan bagian yang bertanggung jawab atas pelayanan makanan dan minuman di hotel. Bagian tersebut merupakan sarana mutlak yang harus disediakan hotel untuk dapat dikategorikan dalam hotel berbintang, dimana tamu akan terpenuhi kebutuhan makanan dan minuman.

Dalam Food and Beverage Department. dibagi menjadi 2 bagian yaitu Food and Beverage Service dan Food and Beverage Product. Masing masing dari bagian ini memiliki tanggung jawab namun masih saling berhubungan. Secara garis besar Food and Beverage Service bertanggung jawab atas operasional restaurant dan
Food and Beverage Product bertanggung jawab atas tersedianya produk makanan dan minuman yang tertera pada buku menu.

Dalam Food and Beverage Product dibagi lagi menjadi 2 section yaitu Hot kitchen dan Pastry. Pastry sendiri merupakan bagian yang bertanggung jawab atas tersedianya aneka kue,roti dan dessert pada jamuan makan. Dalam kesehariannya karyawan pastry akan melakukan pembagian kerja untuk meningkatkan efisiensi kerja. Tidak jarang dalam pembagian kerja karyawan akan melakukan kesalahan yang menyebabkan efisiensi kerja karyawan menurun. Hal itu dapat mempengaruhi kelanjutan operasional pastry.

Tujuan dalam penelitian ini adalah untuk mengetahui cara pembagian tugas yang tepat guna meningkatkan efisiensi kerja karyawan pastry, mengetahui tingkat efisiensi kerja karyawan pada bagian pastry, dan mengetahui dan menganalisa pengaruh pembagian kerja terhadap efisiensi kerja karyawan pastry. 


\section{METODE PENELITIAN}

Pengumpulan data pada penelitian ini dilakukan dengan cara 3 cara, yaitu wawancara, observasi, dan kuesioner. Teknik analisis data yang digunakan pada penelitian ini adalah analis regresi. Menurut Sugiyono (2017:260), Analisis regresi digunakan untuk memprediksikan seberapa jauh perubahan nilai variabel terikat, bilai nilai variabel bebas di manipulasi, dirubah- rubah atau dinaik turunkan. Analisis regresi linier sederhana sendiri didasarkan pada hubungan fungsional ataupun kausal satu variabel bebas dengan satu variabel terikat. Dengan menggunakan analisis ini maka akan mengukur perubahan variabel terikat berdasarkan perubahan variabel bebas. Untuk mengetahui sejauh mana pengaruh yang diperkirakan atara pembagian kerja dengan efisiensi kerja dilakukan dengan rumus regesi linier sederhana, sebagai berikut

\begin{tabular}{c}
\hline$\hat{\mathbf{Y}}=\mathbf{a}+\mathbf{b} \mathbf{X}$ \\
(Sumber : Sugiyono, \\
2017:261)
\end{tabular}

Keterangan :

$\hat{Y}=$ Subyek dalam variabel dependen/ terikat yang diprediksikan

$\mathrm{a}=$ Harga $Y$ ketika harga $X=0$ ( harga konstan)

$\mathrm{b}=$ Angka arah atau koefesien regresi, yang menunjukkan angka peningkatan ataupun penurunan variabel terikat yang didasarkan pada perubahan variabel bebas. Bila $(+)$ arah garis naik, dan bila ( - ) maka arah garis turun

$X$ = Subyek pada variabel independen yang mempunyai nilai tertentu.

Berdasakan persamaan diatas, makan a dan $\mathrm{b}$ dapat diketahui dengan menggunakan rumus berikut : 


$$
\begin{aligned}
\mathrm{a}=\frac{\left(\sum \mathrm{y}\right)\left(\sum \mathrm{x}^{2}\right)-\left(\sum \mathrm{x}\right)}{\left(\sum \mathrm{xy}\right)} \\
\mathrm{n}\left(\sum \mathrm{x}^{2}\right)-\left(\sum \mathrm{x}\right)^{2}
\end{aligned}
$$

Rumus persamaan regresi yang telah ditemukan dapat digunkana untuk melakukan prediksi bagaimana individu dalam variabel terikat akan terjadi bila indiidu dalam variabel bebas ditetapkan.

a. Uji Hipotesis hubungan antara dua variabel

Ho : Tidak ada hubungan antara pembagian kerja terhadap efisiensi kerja

$$
\mathrm{b}=\frac{\mathrm{n}\left(\sum \mathrm{xy}\right)-\left(\sum \mathrm{x}\right)\left(\sum \mathrm{y}\right)}{\mathrm{n}\left(\sum \mathrm{x}^{2}\right)-\left(\sum \mathrm{x}\right)^{2}}
$$

Ha : Ada hubungan antara pembagian kerja terhadap efisiensi kerja

Antara nilai pembagian kerja dengan nilai efisiensi kerja tiap bulan dapat dihitung kolerasinya. Hal itu untuk mengetahui arah dan kuatnya hubungan antara dua variabel. Dengan rumus sebagai berikut:

$$
r=\frac{n \sum x y-\sum x \sum y}{\sqrt{\left[n\left(\sum x^{2}\right)-\left(\sum x\right)^{2}\right]\left[n\left(\sum y^{2}\right)-\left(\sum y\right)^{2}\right]}}
$$

b. Koefesian Determinasi $\mathrm{R}^{2}$

$\mathrm{R}^{2}$ merupakan perbandiangn variasi $Y$ yang dijelaskan oleh $X$ secara bersama- sama dibanding dengan variasi total $Y$

\section{HASIL DAN PEMBAHASAN}

Berdasarkan hasil penelitian yang dilakukan, menunjukkan bahwa ada pengaruh positif dan signifikan antara pembagian kerja terhadap efisiensi kerja karyawan pastry. Hal ini terlihat dari hasil regresi linear sederhana dimana diperoleh persamaan $\mathrm{Y}=10,870+0,739 \mathrm{X}$ yang berati bahwa dalam persamaan tersebut diketahui konstanta sebesar 10,870 yang berati tanpa ada pembagian kerja maka skor untuk 
efisiensi kerja karyawan sebesar 10,870 .

Berdasarkan regresi $b$ bertanda positif maka dapat diartikan bahwa terdapat pengaruh yang positif atara Pembagian kerja dan Efisiensi kerja. Bentuk pengaruh yang diperoleh dari persamaan tersebut adalah jika variabel pembagian kerja ditingkatkan sebesar satu point maka akan diikuti dengan meningkatnya Efisiensi kerja sebesar 0,739, sebaliknya jika skor variabel Pembagian kerja menurun satu point maka akan diikuti dengan menurunnya Efisiensi kerja sebesar 0,739 .

Keeratan hubungan antara Pembagian kerja dan Efisiensi kerja karyawan adalah 0,983 harga koefesien kolerasi bertanda positif tersebut menunjukkan adanya hubungan positif antara pembagian kerja dengan Efisiensi kerja karyawan. Dengan demikian semakin baik pembagian kerja maka akan semakin tinggi efisiensi kerja karyawan dan sebaliknya semakin rendah Pembagian kerja makan akan semakin menurun Efisiensi kerja karyawan.

Besarnya pengaruh pembagian kerja terhadap efisiensi kerja karyawan $\left(\mathrm{r}^{2}\right)$ adalah sebesar 96,7\% hal ini menunjukkan pengaruh yang besar terhadap Efisiensi kerja. Sedangkan sisanya 3.3\% Efisiensi kerja dipengaruhi oleh variabel lain.

\section{KESIMPULAN}

Penelitian mengenai Pengaruh Pembagian Kerja Guna Meningkatkan Efisiensi Kerja Karyawan Pastry di Hotel Santika Premiere Malang ini mengahasilkan kesimpulan sebagai berikut :

1. Tingkat efisiensi kerja karyawan pastry dapat dikatakan kurang baik. Hal itu disimpulkan dari jawaban karyawan di kuesioner. Beberapa karyawan merasa belum mampu menyelesaikan pekerjaan pada waktu yang ditentukan, beban kerja yang ada tidak sesuai dengan jam kerja.

2. Berdasarkan hasil penelitian dari variabel pembagian kerja berpengaruh secara signifikan terhadap efisiensi kerja karyawan pastry di Hotel Santika Premiere Malang sebesar 96,7 \%. Dapat ditarik kesimpulan dari data kuesioner yang didapat oleh 
peneliti adalah pembagian kerja yang ada kurang tepat. Pembagian kerja tidak merata. Karyawan belum mampu menyelesaikan tugas tepat waktu, beban kerja kurang sesuai dengan kemampuan, waktu kerja, dan latar belakang pendidikan karyawan. Karyawan juga kurang nyaman dengan pekerjaan yang dibebankan.

Berdasarkan hasil penelitian yang telah diperoleh dalam penelitian ini maka mengharuskan peneliti untuk memberikan sarannya. Saran dari penelitian ini adalah Peneliti berharap dengan hasil penelitian ini dapt digunakan sebagai alat motivasi agar dapat terus meningkatkan dan memperbaiki pembagian kerja agar efisiensi kerja karyawan terus meningkat.

\section{DAFTAR PUSTAKA}

P.H, Bartono. S., \& E.M, Ruffino. S. (2005). Dasar - Dasar Food Product. Yogyakarta: Andi.

Patriasih, \& Sudewi. (2005). Modul Mata Kuliah Patiseri. Bandung: Tidak diterbitkan. Rumekso. (2002). Housekeeping Hotel. Yogyakarta: Andi.

Subagjo, A. (2007). Manajemen Pengolahan Kue dan Roti. Yogyakarta: Graha Ilmu.

Sugiyono. (2017). Statistika Untuk Penelitian. Bandung: Alfabeta.

Syamsi, I. (2007). Efisiensi, Sistem, dan Prosedur Kerja. Jakarta: Bumi Aksara.

Gie, The Liang (2000). Administrasi Perkantoran. Yokyakarta : Modern Liberty

Wibowo, S. (2007). Petunjuk Mendirikan Perusahaan kecil. Jakarta: Niaga Swadaya. 